\title{
Estudo de Dosagens Visando Obter Concretos para Obras de Pequeno Porte
}

Dosages Study Aiming to Get Concretes for Small Works

Estudio de Dosificacións con el Objetivo de Obtener Concreto para Pequeñas Obras

Bruna de Oliveira Lima Ricci

Aluna de graduação, UNESP - FEIS, Brasil ricci.bruna@hotmail.com

Adriana Maria Pereira Aluna de doutorado do PPGCM, UNESP - FEIS, Brasil Professora Auxiliar, IFSP - Campus Presidente Epitácio/SP, Brasil. adrianapereiradu@gmail.com

Jorge Luís Akasaki Professor Adjunto, UNESP - FEIS, Brasil jorge.akasaki@gmail.com 


\section{RESUMO}

Nas cidades brasileiras, para obras de pequeno porte, ainda é comum fazer a dosagem do concreto empiricamente, o que tem gerado altos custos nas construções e má qualidade do produto final, visto que a dosagem empírica não considera a relação entre a variabilidade dos materiais e as propriedades do concreto. $O$ principal objetivo da pesquisa foi construir um Diagrama de Dosagem, a partir do 'Método de Dosagem de Concreto IPT/EPUSP', para ser utilizado como referência para a produção de concreto em obras de pequeno porte pela Prefeitura de Ilha Solteira SP. Foram definidos traços de concretos rico $(1: 3,5)$, médio $(1: 5)$ e pobre $(1: 6,5)$, com abatimentos variando entre 40 a $200 \mathrm{~mm}$ e resistência à compressão entre $16 \mathrm{MPa}$ e $45 \mathrm{MPa}$. Dos 21 traços desenvolvidos, 16, poderão ser utilizados em elementos estruturais, atendendo às prescrições da norma NBR 6118 (2014). Realizou-se também a caracterização do concreto dosado empiricamente, pelo setor de obras da Prefeitura de Ilha Solteira - SP, a fim de se fazer um comparativo entre os métodos empírico e o experimental. Foi observado que para um traço rico (1:3), produzido sem controle da quantidade da água de amassamento, obteve-se uma resistência à compressão 13,64 $\mathrm{MPa}$, não atendendo ao fck mínimo de $20 \mathrm{MPa}$, prescrito pela NBR 6118 (2014). Acredita-se que, o diagrama de dosagem desenvolvido, auxiliará na produção de concretos em obras de pequeno porte, que passarão a ser executados de modo eficiente, atendendo às prescrições das normas, além de promover a otimização dos recursos naturais e econômicos.

Palavras Chaves: Dosagem experimental. Otimização de recursos. Diagrama de dosagem.

\section{ABSTRACT}

In Brazilian cities, it is still common to do the concrete dosage empirically in small works, which has generated high costs in construction and poor quality of the final product, since the empirical dosage does not take into account the relation between the variability of materials and the properties of the concrete. The main goal of this study was to build a dosage diagram, from 'Concrete Dosage Method IPT / EPUSP', to be used as a reference for the production of concrete in small works by the city of Ilha Solteira - SP. Concrete traits were set as rich (1: 3.5), medium (1: 5) and low (1: 6.5) with rebates ranging from 40 to $200 \mathrm{~mm}$ and a compressive strength of $16 \mathrm{MPa}$ and $45 \mathrm{MPa}$. Of the 21 developed traits, 16 can be used in structural elements, meeting the requirements of the NBR 6118 (2014). Also, the characterization of concrete dosed empirically was done, by the industry works of the City of Ilha Solteira - SP, in order to make a comparison between the empirical and experimental methods. It has been observed that for a rich trait (1: 3 ) produced without controlling the amount of mixing water, the resistance to axial compression obtained was $13.64 \mathrm{MPa}$, not meeting the minimum fck of $20 \mathrm{MPa}$, prescribed by NBR 6118 ( 2014 ). It is believed that the dosage diagram developed, will assist in the production of concrete in small works, which will be run more efficiently, meeting the requirements of technical standards, and promoting the optimization of natural and economic resources.

KEY-WORDS: Experimental Dosage. Resourses optimization. Diagram dosages.

\section{RESUMEN}

En las ciudades brasileñas, para pequeñas obras comúnmente se realiza la dosificación del hormigón empíricamente, lo que ha generado altos costos en la construcción y la mala calidad del producto final, puesto que la dosis empírica no tiene en cuenta la relación entre la variabilidad de materiales y propiedades del hormigón. El principal objetivo era construir un esquema de dosificación, a través del 'Método de Dosagem de Concreto IPT/EPUSP', que se utilizará como referencia para la producción de hormigón en pequeñas obras de la ciudad de Ilha Solteira - SP. Mezclas de hormigón se establecieron rico (1: 3,5), media (1: 5) y baja $(1: 6,5)$ con cono entre 40 a $200 \mathrm{~mm}$ y una resistencia a la compresión de $16 \mathrm{MPa}$ y $45 \mathrm{MPa}$. De los 21 dosificaciones desarrollados, 16, se puede usar en elementos estructurales, cumpliendo con los requisitos de la NBR 6118 (2014). También levantó la caracterización de hormigón dosificado empíricamente, funciona las obras del Municipio de Ilha Solteira - SP, con el fin de hacer una comparación entre los métodos empíricos y experimentales. Se ha observado que para un dosificación rica (1:3) en características produce sin el control de la cantidad de agua de mezcla, una resistencia a la compresión axial, se obtuvo 13,64 MPa, que no cumplan una resistencia mínima de compresión de $20 \mathrm{MPa}$, prescrito por NBR 6118 (2014). Se cree que el esquema de dosificación desarrollado, ayudará en la producción de hormigón en las obras pequeñas, que se ejecutan de manera más eficiente, cumpliendo con los requisitos de las normas técnicas, y promover la optimización de los recursos naturales y económicos.

PALABRAS CLAVE: Dosificación. Optimización de recursos. Las dosis diagraman. 


\section{INTRODUÇÃO}

\subsection{DOSAGEM DO CONCRETO}

O estudo de dosagem experimental dos concretos é entendido como os procedimentos necessários para a caracterização da melhor proporção entre os materiais constituintes do concreto (HELENE, 2005). Diversos pesquisadores vêm trabalhando para conseguir a melhor maneira de determinar a proporção de cada material no conglomerado, de maneira a obter-se uma mistura adequada para situações especificas com economia.

Por outro lado, Barbosa e Bastos (2008) mencionam que os traços de concreto constantes em tabelas antigas, ainda hoje muito utilizados na confecção de concretos para obras de pequeno porte, não atendem aos requisitos de qualidade hoje exigidos. Em muitos casos, observa-se que os concretos são produzidos com base na tradição construtiva local, sem qualquer preocupação quanto ao atendimento das prescrições de normas. O teor de argamassa é alto, superior a $55 \%$, o que diminui a possibilidade de nichos de concretagem. 0 abatimento médio é de $173 \mathrm{~mm}$, e mostra que, em geral, os pedreiros preferem trabalhar com concretos de alta fluidez, para possibilitar sua penetração em fôrmas estreitas e envolver as barras da armadura, sendo obtida com adição de grande quantidade de água. Como consequência, os concretos apresentam baixa resistência e alta porosidade.

De acordo com Helene (2005) não existe ainda no Brasil um texto consensual de determinação do estudo de dosagem. Essa inexistência de regulamentação e norma nacional faz com que existem vários métodos de dosagens, com diferentes procedimentos e parâmetros publicados e utilizados por vários pesquisadores. Pode-se observar nas obras de pequeno porte a utilização da dosagem empírica, também conhecida como dosagem não experimental, na qual a proporção dos materiais do concreto é feita em bases arbitrárias, na experiência do construtor ou na própria tradição (PETRUCCI, 1998).

O objetivo da dosagem é produzir um material que ofereça um desempenho que atenda aos requisitos previamente estabelecidos, sendo os mais importantes a trabalhabilidade, a resistência mecânica, a durabilidade e a economia. A dosagem do concreto é feita para que possa também ser realizada uma minimização dos custos. Uma boa dosagem levará em conta uma análise entre os custos dos materiais disponíveis e os possíveis de serem adquiridos. No entanto, é difícil a determinação da combinação mais econômica e que atenda aos requisitos mínimos de desempenho exigidos em projeto, uma vez que dentro de um volume fixo de dosagem a alteração de um componente altera diretamente o outro.

Segundo Tartuce e Giovannetti (1990), a determinação das proporções mais adequadas visa à obtenção de um concreto que:

- Quando fresco, seja trabalhável, mantendo a homogeneidade nas etapas de produção e aplicação (mistura, transporte, lançamento e adensamento);

- Quando endurecido, apresente, na idade especificada, as propriedades exigidas pelo projeto estrutural e a aparência estabelecida no projeto arquitetônico;

- Seja durável, isto é, mantenha suas propriedades pelo menos ao longo da vida útil prevista para as estruturas, resistindo a eventuais reações entre seus componentes e às ações físicas e químicas do meio e;

- Seja econômico. 
Segundo Helene (2005) o método IPT/EPUSP leva em consideração a relação a/c como parâmetro mais importante para o concreto. Sempre que mantida a mesma trabalhabilidade, definidos os materiais da mistura e a relação $a / c$, a resistência e durabilidade do concreto passam a ser únicas. As interações entre as diversas variáveis são regidas pelas conhecidas leis universais de comportamento do concreto. São elas a Lei de Abrams, a Lei de Lyse e a Lei de Priszkulnik \& Kirilos ou Molinari.

A Lei de Abrams envolve a resistência à compressão $(\mathrm{fc})$ com a relação água/cimento $(\mathrm{a} / \mathrm{c})$. Nela ele define que dentro do campo dos concretos plásticos, a resistência física do concreto endurecido varia na razão inversa da relação água-cimento, conforme a equação 1 (PETRUCCI, 1998).

$$
f c=\frac{k 1}{k 2^{a} / c} \quad \text { (Equação 1) }
$$

Onde $k_{1}$ e $k_{2}$ são constantes intrínsecas aos materiais utilizados.

A Lei de Lyse foi desenvolvida por Inge Lyse, que estabeleceu uma função de interação entre a quantidade de massa seca (agregados e cimento) e a relação água-cimento (Equação 2).

$$
m=k 3+k 4 \cdot a / c \quad \text { (Equação 2) }
$$

Onde $m$ é a relação de agregados secos por cimento, em massa, e as constantes $k_{3}$ e $k_{4}$ dependem dos materiais empregados.

A Lei de Molinari correlaciona o fator de consistência do concreto com a quantidade de agregado empregado $(m)$ e o consumo de cimento necessário (C) (Equação 3).

$$
C=\frac{1000}{k 5+k 6 . m} \quad \text { (Equação 3) }
$$

As constantes $k_{5}$ e $k_{6}$ são determinadas pelos materiais em laboratório.

O método inicia-se com a elaboração do traço médio $(1: 5,0)$. Para isso, o primeiro passo é a determinação do teor ideal de argamassa. É considerada uma das etapas mais importantes, pois a falta de argamassa acarreta aumento da porosidade do concreto e falhas de concretagem. Este parâmetro que determina a adequabilidade do concreto fresco lançado na fôrma. Argamassa em excesso melhora a aparência do concreto, porém aumenta seu custo por metro cúbico, e também, o risco de fissuração por origem térmica (reação de hidratação do cimento) e por retração de secagem. Sendo assim, o teor de argamassa ideal deve ser o mínimo teor necessário para que não haja aumento da porosidade do concreto.

O consumo de cimento por metro cúbico de concreto pode ser determinado utilizando as massas específicas dos seus componentes, baseado nas leis comportamentais do concreto, conforme a equação 4 :

Onde:

$$
C=\frac{1000-(\% a r)}{\frac{1}{\gamma c}+\frac{a}{\text { rareia }}+\frac{p}{\text { rbrita }}+\frac{a / c}{\text { үágua }}} \quad \text { (Equação 4) }
$$

$\gamma_{c}=$ massa específica do cimento;

$\gamma_{\text {água }}=$ massa específica da água;

$\gamma_{\text {areia }}=$ massa específica da areia;

$\gamma_{\text {brita }}=$ massa específica da brita;

$\%_{a r}=$ percentual de ar incorporado ao concreto;

$a=$ agregado miúdo; 


$$
p=\text { agregado graúdo }
$$

Com os mesmos materiais e mesmo teor ideal de argamassa obtido no traço 1:5, elaboram-se os traços rico $(1: 3,5)$ e pobre $(1: 6,5)$, com base nas correlações entre os traços feitas pelo método. Os dois traços devem atender a mesma faixa de abatimento especificado. Para cada um dos traços produzidos, são feitas amostras (corpos de prova) que devem ser curadas adequadamente e, nas idades pré-estabelecidas, rompidas em prensa universal. Com base nas leis comportamentais do concreto e com os dados obtidos no estudo experimental, deve ser construído as correlações entre traço de concreto e relação água/cimento, $\mathrm{m}=\mathrm{f}(\mathrm{a} / \mathrm{c})$; consumo de cimento e traço, $C=f(m)$, dando origem ao conhecido diagrama de dosagem. $O$ diagrama é composto pelas três curvas mencionadas anteriormente. Obtém-se uma interação entre a resistência à compressão, o consumo de cimento, consistência e relação água/cimento, conforme se apresenta na Figura 1.

Figura 1: Diagrama de dosagens dos concretos de cimento Portland.

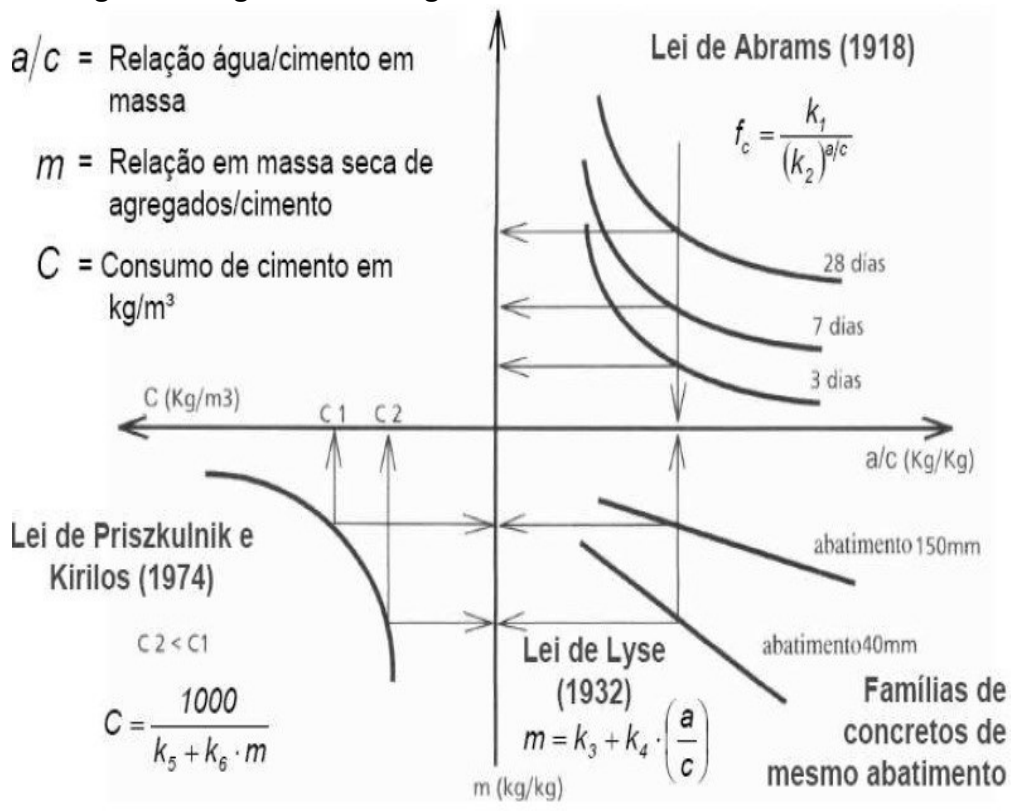

Fonte: HELENE; TERZIAN, 1992

\section{OBJETIVOS}

\subsection{OBJETIVO GERAL}

O objetivo geral do estudo foi o de construir um Diagrama de dosagens, por meio do 'Método de Dosagem de Concreto IPT/EPUSP', para ser utilizado como referência em obras de pequeno porte a serem realizadas pela Prefeitura Municipal de Ilha Solteira - SP, a fim de se otimizar o uso de recursos naturais.

\subsection{OBJETIVOS ESPECIFICOS}

Como objetivos específicos tem-se: 
- Caracterização física e mecânica do concreto dosado de modo empírico, produzido pelos servidores da Prefeitura da cidade de Ilha Solteira - SP;

- Caracterização física e mecânica dos concretos produzidos em laboratório, segundo o 'Método de Dosagem de Concreto IPT/EPUSP' e

- Comparação dos métodos de dosagens, segundo o controle dos materiais empregados e padrão de qualidade exigido por norma.

Na fase experimental, foi seguida a proposta de Helene e Terzian (1992) que parte do princípio que são necessários três pontos para poder montar o diagrama de dosagem, que correlaciona a resistência à compressão, relação água /cimento, traço e consumo de cimento. 0 início do estudo experimental partiu da avaliação preliminar, com mistura em betoneira do traço médio 1:5 (cimento: agregados secos totais, em massa). Baseado nas informações obtidas do traço médio, foram confeccionados traços ricos $(1: 3,5)$ e traços pobres $(1: 6,5)$. Para cada traço foi feito o abatimento do concreto variando de 40 a $180 \pm 20 \mathrm{~mm}$, para um Teor de argamassa igual a 49\%; com um percentual de ar incorporado ao concreto de $15 \%$.

As amostras do traço produzidos empiricamente foram coletadas no canteiro de obras da Prefeitura de Ilha Solteira - SP.

\subsection{MATERIAIS UTILIZADOS}

\subsubsection{Cimento}

Nesta pesquisa, utilizou-se o cimento CP II Z (Cimento Portland composto com pozolana) para a elaboração dos concretos produzidos em obras e em laboratório, pelo fato de seu emprego ser em larga escala para obras públicas da cidade de Ilha Solteira - SP. A caracterização do cimento utilizando estava dentro das especificações da NBR 11578 (1997).

\subsubsection{Agregados}

A areia utilizada como agregado miúdo, apresenta a sua caracterização na tabela 1, a seguir. Tabela 1 - Caracterização do agregado miúdo

\begin{tabular}{|c|c|c|c|c|c|c|c|c|c|}
\hline \multirow{2}{*}{$\begin{array}{l}\varnothing \text { max. } \\
(\mathrm{mm})\end{array}$} & \multirow{2}{*}{$\begin{array}{c}\text { Módulo } \\
\text { de } \\
\text { finura }\end{array}$} & \multicolumn{3}{|c|}{ Massa específica $\left(\mathrm{g} / \mathrm{cm}^{3}\right)$} & \multicolumn{2}{|c|}{$\begin{array}{l}\text { Massa unitária } \\
\qquad\left(\mathrm{g} / \mathrm{cm}^{3}\right)\end{array}$} & \multirow{2}{*}{$\begin{array}{c}\text { Absorção } \\
\text { (\%) }\end{array}$} & \multirow{2}{*}{$\begin{array}{c}\text { Pulverulento } \\
\text { (\%) }\end{array}$} & \multirow{2}{*}{$\begin{array}{l}\text { Matéria } \\
\text { Orgânica }\end{array}$} \\
\hline & & s.s.s. & seca & aparente & Solta & $\begin{array}{c}4 \% \text { de } \\
\text { umidade }\end{array}$ & & & \\
\hline 2,36 & 2,07 & 2,639 & 2,651 & 2,631 & 1,543 & 1,218 & 0,28 & 0,86 & + Clara \\
\hline
\end{tabular}

Fonte: Elaborada pelos autores.

A brita utilizada como agregado graúdo, foi a de origem basáltica com granulometria máxima de 19 mm e sua caracterização é apresentada na Tabela 2.

Tabela 2 - Caracterização do agregado graúdo 


\begin{tabular}{ccccccccc}
\hline \multirow{2}{*}{$\begin{array}{c}\text { max. } \\
(\mathbf{m m})\end{array}$} & $\begin{array}{c}\text { Módulo } \\
\text { de } \\
\text { finura }\end{array}$ & s.s.s. & seca & aparente & $\begin{array}{c}\text { Massa específica }\left(\mathrm{g} / \mathrm{cm}^{3}\right) \\
\left(\mathbf{g} / \mathrm{cm}^{3}\right)\end{array}$ & $\begin{array}{c}\text { Absorção } \\
(\%)\end{array}$ & $\begin{array}{c}\text { Pulverulento } \\
\text { (\%) }\end{array}$ \\
\hline 19,0 & 6,92 & 2,947 & 2,911 & 3,019 & 1,618 & 1,24 & 0,68 \\
\hline
\end{tabular}

Fonte: Elaborada pelos autores.

\subsection{TRAÇOS DE CONCRETOS EXPERIMENTAIS E EMPÍRICOS}

Pode ser observada na Tabela 3 a composição do traço de concreto utilizado pelo Departamento de Obras da Prefeitura Municipal de Ilha Solteira.

Tabela 3: Composição dos traços de concreto para dosagem empírica

\begin{tabular}{ccccccc}
\hline Traço & $\begin{array}{c}\text { Slump } \\
(\mathbf{m m})\end{array}$ & a/c & $\begin{array}{c}\text { Consumo de } \\
\text { Cimento } \\
\left(\mathbf{k g} / \mathrm{m}^{\mathbf{3}}\right)\end{array}$ & $\begin{array}{c}\text { Consumo de } \\
\text { Areia }\left(\mathrm{kg} / \mathrm{m}^{3}\right)\end{array}$ & $\begin{array}{c}\text { Consumo } \\
\text { de Brita } \\
\left(\mathbf{k g} / \mathrm{m}^{\mathbf{3}}\right)\end{array}$ & $\begin{array}{c}\text { Consumo } \\
\text { de Água } \\
\left(\mathbf{k g} / \mathrm{m}^{3}\right)\end{array}$ \\
\hline $1: 3$ & 190 & 0,63 & 481,4 & 722,10 & 722,10 & 303,28 \\
\hline
\end{tabular}

Fonte: Elaborada pelos autores.

A tabela 4 apresenta a dosagem experimental, seguindo a proposta do método do IPT/EPUSP.

Tabela 4: Composição dos traços de concreto para dosagem experimental

\begin{tabular}{ccccccc}
\hline TRAÇO & $\begin{array}{c}\text { SLUMP } \\
(\mathbf{m m})\end{array}$ & $\mathbf{a / c}$ & $\begin{array}{c}\text { Consumo } \\
\text { Ce } \\
\text { Cimento } \\
\left(\mathbf{k g} / \mathbf{m}^{3}\right)\end{array}$ & $\begin{array}{c}\text { Consumo de } \\
\text { Areia } \\
\left(\mathbf{k g} / \mathbf{m}^{3}\right)\end{array}$ & $\begin{array}{c}\text { Consumo } \\
\text { de Brita } \\
\left(\mathbf{k g} / \mathbf{m}^{3} \mathbf{)}\right.\end{array}$ & $\begin{array}{c}\text { Consumo } \\
\text { de Água } \\
\left(\mathbf{k g} / \mathbf{m}^{3} \mathbf{)}\right.\end{array}$ \\
\hline $1: 3,5$ & 40 & 0,395 & 499,93 & 767,39 & 967,36 & 197,47 \\
$1: 3,5$ & 60 & 0,400 & 498,66 & 765,44 & 964,91 & 199,46 \\
$1: 3,5$ & 80 & 0,405 & 497,40 & 763,51 & 962,47 & 201,45 \\
$1: 3,5$ & 100 & 0,410 & 496,15 & 761,59 & 960,05 & 203,42 \\
$1: 3,5$ & 120 & 0,425 & 492,43 & 755,88 & 952,85 & 209,28 \\
$1: 3,5$ & 140 & 0,440 & 488,76 & 750,25 & 945,75 & 215,05 \\
\hline $1: 5,0$ & 40 & 0,450 & 383,01 & 926,88 & 988,17 & 172,35 \\
$1: 5,0$ & 60 & 0,460 & 381,52 & 923,28 & 984,32 & 175,50 \\
$1: 5,0$ & 80 & 0,470 & 380,05 & 919,72 & 980,53 & 178,62 \\
$1: 5,0$ & 100 & 0,480 & 378,59 & 916,19 & 976,76 & 181,72 \\
$1: 5,0$ & 120 & 0,510 & 374,27 & 905,73 & 965,62 & 190,88 \\
$1: 5,0$ & 140 & 0,520 & 372,86 & 902,32 & 961,98 & 193,89 \\
\hline $1: 6,5$ & 40 & 0,560 & 305,12 & 999,27 & 984,01 & 170,87 \\
$1: 6,5$ & 60 & 0,580 & 303,24 & 993,11 & 977,95 & 175,88 \\
$1: 6,5$ & 80 & 0,590 & 302,31 & 990,07 & 974,95 & 178,36 \\
$1: 6,5$ & 100 & 0,610 & 300,47 & 984,04 & 969,02 & 183,29 \\
$1: 6,5$ & 120 & 0,620 & 299,55 & 981,03 & 966,05 & 185,72 \\
$1: 6,5$ & 140 & 0,640 & 297,74 & 975,10 & 960,21 & 190,55 \\
$1: 6,5$ & 160 & 0,650 & 299,40 & 980,54 & 965,57 & 194,61 \\
$1: 6,5$ & 180 & 0,660 & 298,49 & 977,55 & 962,63 & 197,00 \\
$1: 6,5$ & 200 & 0,680 & 296,70 & 971,69 & 956,86 & 201,76 \\
\hline
\end{tabular}

Fonte: Elaborada pelos autores. 


\subsubsection{Mistura Experimental}

A betoneira foi umedecida e então os materiais foram colocados na betoneira na seguinte ordem: foi adicionado todo o agregado graúdo, o agregado miúdo e aproximadamente metade da água. A betoneira foi ligada para misturar os componentes durante um minuto. Feito isso, foi adicionado a outra parte de água e o cimento. Seguiu-se de mais três minutos de mistura. Foi utilizado, em sequência, três minutos para retirar os materiais retidos nas superfícies internas com auxílio de uma colher de pedreiro. Finalizou-se com mais três minutos de mistura para a homogeneização final. Após a descarga, foi verificado se não ficou retido nas superfícies das paredes e pás da betoneira um volume residual de concreto de mais de $5 \%$ do volume nominal, conforme exigido pela NBR 12655 (2015).

\subsubsection{Slump Test}

O Slump Test foi realizado para verificar as condições de consistência do concreto utilizado, conforme prescrito na norma, NM 67(1998) de determinação da consistência pelo abatimento do tronco de cone.

\subsubsection{Moldagem e Adensamento}

A moldagem dos corpos de prova foi realizada em fôrmas cilíndricas de dimensões $10 \times 20 \mathrm{~cm}$, conforme especificados na norma NBR 5739 (2007). O adensamento do concreto, realizado em função do seu abatimento, foi feito de forma mecanizada utilizando-se uma mesa vibratória por aproximadamente 60 segundos. Os procedimentos de moldagem e adensamento foram realizados de acordo com a NBR 5738 (2015).

\subsubsection{Cura dos Corpos de Prova}

Os corpos de prova foram armazenados em câmara úmida à temperatura de $(23 \pm 2){ }^{\circ} \mathrm{C}$ com umidade relativa superior $95 \%$ e desmoldados $24 \mathrm{~h}$ após o momento de moldagem, conforme prescreve a norma NBR 5738 (2015).

\subsubsection{Capeamento}

O capeamento dos corpos-de-prova foi feito com uma fina camada ( $\leq 3 \mathrm{~mm}$ ) de uma mistura de enxofre $(60 \%)$ e pozolana $(40 \%)$ produzindo uma superfície lisa, plana e bem aderida ao concreto após o endurecimento, atendendo às solicitações da NBR 5738 (2015). 


\subsubsection{Ensaios Físicos e Mecânicos}

O ensaio de resistência à compressão axial foi realizado seguindo as recomendações das normas da ABNT, a saber: NBR 5739 (2007) e NBR 7215 (1997). O ensaio para a determinação da absorção de água, foi executado como prescreve a NBR 9778 (2009). Os ensaios físicos e mecânicos foram realizados aos 28 dias de cura, para 5 corpos de prova para o ensaio mecânico e três corpos de provas para o ensaio de absorção.

\section{$4 \quad$ RESULTADOS E DISCUSSÕES}

Os dados mecânicos foram calculados considerando o desvio relativo máximo, conforme item 3.6.3 da NBR 7215 (1997). Para desvios relativos máximos superiores a 6\%, foram desconsiderados os valores discrepantes e calculadas novas médias, conforme prescreve o item 3.6.4 da NBR 7215 (1997). São apresentados na Tabela 5 os valores obtidos no teste de abatimento (Slump), a relação água cimento $(\mathrm{a} / \mathrm{c})$, o consumo de cimento $(\mathrm{C})$ do traço, a resistência à compressão axial $\left(f_{c k}\right)$, e a absorção de água $(w)$ dos corpos de prova para cada traço executado, à idade de 28 dias.

Tabela 5: Valores obtidos de Slump, a/c, C, fck e w

\begin{tabular}{cccccc}
\hline TRAÇO & SLUMP $(\mathbf{m m})$ & $\mathbf{a} / \mathbf{c}$ & $\mathbf{C}\left(\mathbf{k g} / \mathbf{m}^{\mathbf{3}}\right)$ & fck (MPa) & $\mathbf{w ~ ( \% )}$ \\
\hline $1: 3,5$ & 40 & 0,395 & 499,93 & 44,73 & 5,2 \\
$1: 3,5$ & 60 & 0,400 & 498,66 & 43,20 & 5,2 \\
$1: 3,5$ & 80 & 0,405 & 497,40 & 41,26 & 5,2 \\
$1: 3,5$ & 100 & 0,410 & 496,15 & 39,44 & 5,5 \\
$1: 3,5$ & 120 & 0,425 & 492,43 & 38,19 & 5,6 \\
$1: 3,5$ & 140 & 0,440 & 488,76 & 37,26 & 5,6 \\
\hline $1: 5,0$ & 40 & 0,450 & 383,01 & 34,83 & 5,8 \\
$1: 5,0$ & 60 & 0,460 & 381,52 & 34,16 & 5,8 \\
$1: 5,0$ & 80 & 0,470 & 380,05 & 30,82 & 5,8 \\
$1: 5,0$ & 100 & 0,480 & 378,59 & 28,23 & 6,0 \\
$1: 5,0$ & 120 & 0,510 & 374,27 & 27,66 & 6,0 \\
$1: 5,0$ & 140 & 0,520 & 372,86 & 27,01 & 6,0 \\
\hline $1: 6,5$ & 40 & 0,560 & 305,12 & 24,86 & 6,1 \\
$1: 6,5$ & 60 & 0,580 & 303,24 & 23,09 & 6,2 \\
$1: 6,5$ & 80 & 0,590 & 302,31 & 21,39 & 6,2 \\
$1: 6,5$ & 100 & 0,610 & 300,47 & 20,77 & 6,3 \\
$1: 6,5$ & 120 & 0,620 & 299,55 & 19,79 & 6,3 \\
$1: 6,5$ & 140 & 0,640 & 297,74 & 18,53 & 6,4 \\
$1: 6,5$ & 160 & 0,650 & 299,40 & 18,99 & 6,4 \\
$1: 6,5$ & 180 & 0,660 & 298,49 & 17,16 & 6,5 \\
$1: 6,5$ & 200 & 0,680 & 296,70 & 15,65 & 6,5 \\
\hline
\end{tabular}

Fonte: Elaborada pelos autores.

Como pode ser observado pela tabela 5, para cada incremento da relação a/c houve um aumento no abatimento do concreto, uma redução na resistência à compressão e um menor consumo de cimento para uma mesma quantidade de agregado. Outro fator interessante que deve ser observado é o aumento da absorção de água, que está relacionado ao aumento no índice de vazios dentro do concreto o que leva à confirmação da lei de Molinari.

Foi realizada no canteiro de obras da Prefeitura de llha Solteira a produção do concreto normalmente feito pelos trabalhadores para as obras de pequeno porte da cidade (Figura 2). 
Este foi produzido de forma totalmente empírica, ou seja, sem a utilização de nenhuma tabela de auxílio ou material de apoio, somente com a experiência do trabalhador. Os materiais foram lançados na betoneira sem nenhuma ordem lógica, assim como não houve qualquer controle na quantidade de água colocada.

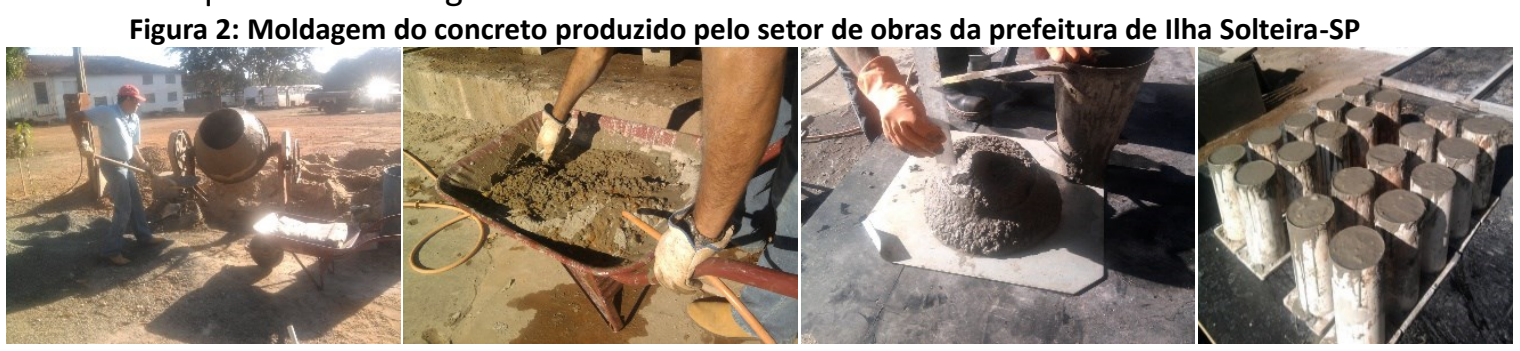

Fonte: Elaborada pelos autores.

O concreto produzido foi também submetido ao teste de abatimento, resistência à compressão axial e absorção de água. Os resultados obtidos são apresentados na Tabela 6.

Tabela 6: Valores obtidos de slump, fck e w do concreto executado pela Prefeitura de Ilha Solteira

\begin{tabular}{cccc}
\hline TRAÇO & $\begin{array}{c}\text { SLUMP } \\
(\mathbf{m m})\end{array}$ & fck (MPa) & w (\%) \\
\hline $1: 3$ & 190 & 13,64 & 9,3 \\
\hline
\end{tabular}

Fonte: Elaborada pelos autores.

Como pode ser observado na Tabela 6, o concreto obtido apresentou Slump muito elevado $(190 \mathrm{~mm})$, possuindo grande trabalhabilidade, mas em contrapartida, um valor de resistência à compressão axial muito baixo, assim como um índice de vazios muito elevado. Ressalta-se ainda que em função da baixa eficiência da dosagem, a resistência característica fck do concreto produzido (13,64 MPa) não atende ao fck mínimo de $20 \mathrm{MPa}$ exigido pela NBR 6118 (2014).

Em comparação com as dosagens experimentais, a dosagem empírica analisada apresentou corpos de prova com resistência mecânica muito inferior à resistência obtida pela dosagem racional, mostrando que uma das maiores influências nas misturas empíricas é o controle do fator água/cimento das misturas, o que confirma a afirmação de Helene (2005), de que a relação a/c é o parâmetro mais importante para o concreto.

Observa-se ainda, que quando se analisa os traços experimentais e empíricos para abatimentos e relação a/c próximos (Tabela 7), os traços experimentais, mesmo utilizando um concreto pobre (1:6,5), obtêm-se uma resistência $26 \%$ maior do que o concreto produzido em campo e que apresenta um consumo alto de cimento na sua composição (1:3). Logo, mesmo diminuindo a quantidade de cimento no concreto, a sua confecção fica mais viável, apenas otimizando a relação dos materiais. Ressalta-se ainda, com base na tabela de 5 , que para a dosagem 1:3, realizada empiricamente, esperava-se um valore de fck superior a $30 \mathrm{MPa}$. 
Tabela 7: Comparação dos valores mecânicos e físicos da dosagem experimental e empírica

\begin{tabular}{cccccc}
\hline TRAÇO & SLUMP $(\mathbf{m m})$ & a/c & $\mathbf{C}\left(\mathbf{k g} / \mathbf{m}^{\mathbf{3}}\right)$ & fck (MPa) & $\mathbf{w}(\%)$ \\
\hline $1: 6,5$ & 180 & 0,660 & 298,49 & 17,16 & 6,5 \\
$1: 3,0$ & 190 & 0,630 & 481,40 & 13,64 & 9,3 \\
\hline
\end{tabular}

Fonte: Elaborada pelos autores.

Com base nesses resultados, fica evidente a importância de se adotar um parâmetro de dosagem. Todos os fatores apresentados anteriormente levam a uma baixa durabilidade na vida útil da construção, além de possíveis problemas estruturais.

Utilizando-se do diagrama de dosagens, poderá então se obter um concreto mais sustentável, com o consumo suficientemente necessário de cimento para a trabalhabilidade requerida ao fim destinado e com as características físicas e mecânicas mínimas exigidas pela norma.

Em posse dos dados obtidos, foi feito o Diagrama de dosagens (Figura 2), que relaciona a resistência à compressão com a relação água cimento (Lei de Abrams), a relação entre $\mathrm{m}$ (massa seca de agregados/massa cimento) com a relação água cimento (a/c) (Lei de Lyse) e a relação entre o consumo de cimento por metro cúbico (C) com a relação de agregados secos por cimento, em massa $(\mathrm{m})$, conhecida como - Lei de Molinari. O Diagrama de dosagens define o comportamento do concreto para os mesmos materiais utilizados.

Figura 2: Diagrama de dosagem

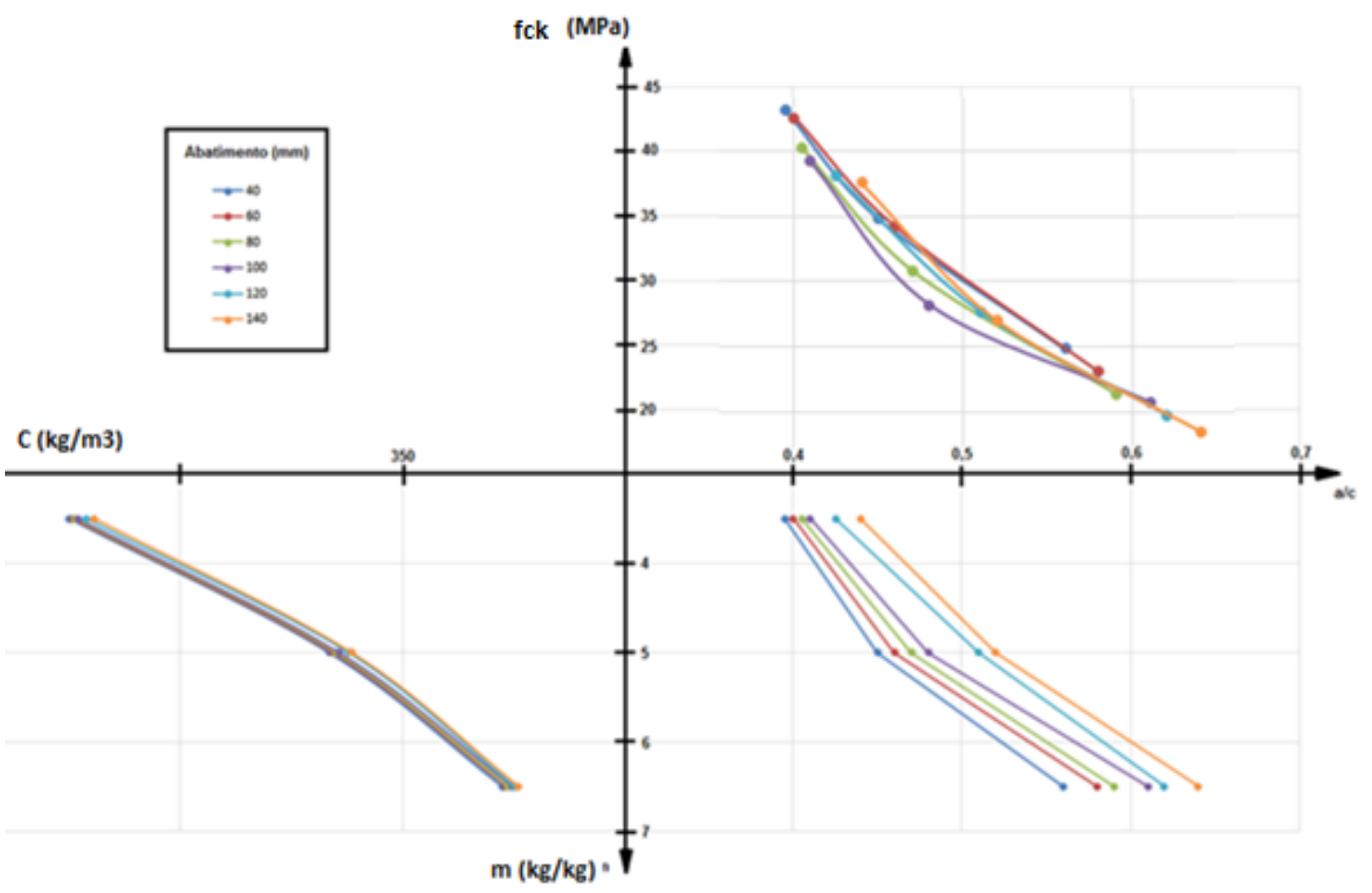

Fonte: Elaborada pelos autores. 
Nota-se que a utilização do diagrama de dosagem é prático, em posse do diagrama e com apenas um simples treinamento o trabalhador realiza a dosagem do concreto, uma vez definida o valor da resistência (fck) que se pretende obter, de acordo com a aplicação.

\section{CONCLUSÃO}

Conclui-se que:

- Mesmo utilizando um traço rico, a falta de controle dos parâmetros que definem as características físicas e mecânicas do concreto, levaram, a produção de um material com baixa resistência e durabilidade. No caso estudado o traço rico (1:3) produzido empiricamente, teve em sua composição um alto consumo de cimento, no entanto a resistência à compressão axial foi baixa e o teor de absorção alto, quando se compara com os traços produzidos em laboratórios, a partir da dosagem experimental (Método IPT/EPUSP).

- Observa-se ainda, que os traços médios e pobres, dosados experimentalmente tiveram um melhor desempenho do que o traço rico, dosado empiricamente, isso se deve à falta de controle na quantidade de água de amassamento, a não consideração do teor de umidade dos agregados, a mistura dos materiais em betoneira, acima da capacidade do equipamento e ao adensamento manual realizado de forma inadequada, nas obras. Logo o melhor controle das dosagens e do processo de concretagem nas obras, garantem que o concreto produzido esteja dentro dos padrões mínimos exigido pela NBR 6118 (2014);

- Assim, os traços de concreto e o diagrama de dosagem, apresentados neste trabalho devem ser vistos como sugestões para um proporcionamento inicial, para a produção de concretos em obras de pequeno porte na Prefeitura Municipal de Ilha Solteira, no entanto, deve-se levar em conta as características do cimento e dos agregados a serem utilizados, realizando as correções necessárias para obter o abatimento e a resistência à compressão esperadas e

- Com a construção do diagrama de dosagens, não será necessário a utilização de antigos padrões e tabelas antes utilizados pelos trabalhadores, assim como a dosagem feita de forma empírica e aleatória. Com o diagrama em mãos, o setor de obras da Prefeitura Municipal de Ilha Solteira-SP poderá produzir um concreto gerando grande economia de materiais, reduzindo principalmente o consumo de cimento.

\section{AGRADECIMENTOS}

Os autores agradecem ao Departamento de Obras da Prefeitura Municipal de Ilha Solteira e ao Laboratório Central de Engenharia Civil da UNESP - FEIS. 


\section{REFERÊNCIAS}

ASSOCIAÇÃO BRASILEIRA DE NORMAS TÉCNICAS - ABNT. NBR 5738: Concreto - Procedimento para moldagem e cura de corpos-de-prova. Rio de Janeiro, 2015. 9p.

ASSOCIAÇÃO BRASILEIRA DE NORMAS TÉCNICAS - ABNT. NBR 5739: Concreto - Ensaio de compressão de corposde-prova cilíndricos: procedimento. Rio de Janeiro, 2007. 9p.

ASSOCIAÇÃO BRASILEIRA DE NORMAS TÉCNICAS - ABNT. NBR 6118: Projeto de estruturas de concreto Procedimento. Rio de Janeiro, 2014. 238p.

ASSOCIAÇÃO BRASILEIRA DE NORMAS TÉCNICAS - ABNT. NBR 7215: Cimento Portland - Determinação da Resistência à Compressão. Rio de Janeiro, 1997. 8p.

ASSOCIAÇÃO BRASILEIRA DE NORMAS TÉCNICAS - ABNT. NBR 9778: Argamassa e concreto endurecidos Determinação da absorção de água, índice de vazios e massa específica. Rio de Janeiro, 2009. 4p.

ASSOCIAÇÃO BRASILEIRA DE NORMAS TÉCNICAS - ABNT. NBR 11578: Cimento Portland composto - Especificação. Rio de Janeiro, 1997. 5p.

ASSOCIAÇÃO BRASILEIRA DE NORMAS TÉCNICAS - ABNT. NBR 12655: Concreto de cimento Portland - Preparo, controle e recebimento - Procedimento. Rio de Janeiro, 2015. 23p.

ASSOCIAÇÃO BRASILEIRA DE NORMAS TÉCNICAS - ABNT. NBR NM 67: Concreto - Determinação da consistência pelo abatimento do tronco de cone. Rio de Janeiro, 1998. 8p.

BARBOZA, Marcos R.; BASTOS, Paulo Sérgio. Traços de concreto para obras de pequeno porte. Concreto e Construção, v. 36, p. 32-36, 2008.

HELENE, P. R. L., TERZIAN, P. Manual de dosagem e controle do concreto. São Paulo: Pini; Brasília, DF: SENAl, 1992. p. 350.

HELENE, P. CONCRETO: Ensino, Pesquisa e Realizações. Capítulo 15: Dosagem dos Concretos de Cimento Portland. Ed. G.C. Isaia. São Paulo. 2005. p. 1600.

PETRUCCI, E. G. R. Concreto de Cimento Portland; 13a ed. Ed. Globo, São Paulo. 1998. p. 307.

TARTUCE, R.; GIOVANNeTtI, E. Princípios Básicos de Cimento Portland. São Paulo: Copyright editora PINI LTDA, 1990. 107p. 